\title{
ChemComm
}

Check for updates

Cite this: Chem. Commun., 2019, 55, 2297

Received 12th December 2018 Accepted 24th January 2019

DOI: $10.1039 / \mathrm{c} 8 \mathrm{cc} 09850$

rsc.li/chemcomm

\section{A mixed molecular salt of lithium and sodium breaks the Hume-Rothery rules for solid solutions $\dagger$}

\author{
Monica Lestari and Matteo Lusi (D) *
}

\begin{abstract}
The first molecular solid solution of lithium and sodium ions is reported. In spite of the different chemical and structural properties of the parent compounds, the two cations form a homogeneous mixed phase with the isoorotate ion. Such observation appears in contrast with the Hume-Rothery principles for solid solutions. Furthermore the mixed salts in the series are thermally stable up to $100{ }^{\circ} \mathrm{C}$ and non-hygroscopic, which makes them relevant for their potential use as a lithium drug substance.
\end{abstract}

Solid solutions have long been studied in chemical and pharmaceutical research. ${ }^{1}$ Such phases allow the variation of composition and properties in continuum, enabling material design and fine-tuning. ${ }^{2}$ Unfortunately, molecular solubility in the solid state is more limited than in the liquid state. ${ }^{3}$ For example, the Hume-Rothery rule prescribes that complete miscibility in metals and inorganic salts requires isovalent atoms whose size (atomic or ionic radius) differs by less than $15 \%$, as well as crystal isomorphism of the pure (parent) substances. ${ }^{4,5}$ In molecular mixed crystals it has been suggested that molecular isostructurality is also required, ${ }^{6}$ although exceptions are reported. ${ }^{7}$ Such strict rules explain why solid solutions are rarer than single component crystals and co-crystals. Furthermore, the difficulty in finding molecular components that satisfy the above conditions is an obstacle to the development of solid solutions into products for real world applications.

Lithium ion is the active pharmaceutical ingredient (API) of choice in the treatment of bipolar disorder and is listed as "essential medicine" by the World Health Organization. Among the many available compounds, lithium citrate and lithium carbonate are the only FDA approved salts for therapeutic purposes. Others, like lithium orotate, are commercially available as supplements. In spite of their high efficacy, these

Bernal Institute, University of Limerick, Castletroy, Ireland.

E-mail: matteo.lusi@ul.ie

$\dagger$ Electronic supplementary information (ESI) available: Experimental procedure, supplementary figures and tables. CCDC 1880097, 1880098, 1884568 and 1884569. For ESI and crystallographic data in CIF or other electronic format see DOI: $10.1039 / \mathrm{c} 8 \mathrm{cc} 09850 \mathrm{f}$ drugs are characterised by a narrow therapeutic window, whereby the difference between the serum concentrations required for effectiveness and toxicity is small. As a consequence, the drug must be administrated through medical centres that monitor lithium levels in the blood. ${ }^{8}$

Recent publications describe drug-drug ionic cocrystals (ICC) such as piracetam with lithium bromide and lithium chloride $^{9}$ or lithium salicylate and $\mathrm{L}$-proline ${ }^{10,11}$ that could guarantee higher lithium absorption whilst reducing toxicity. Such products could enable a simpler administration protocol, increasing patience compliance and reducing the costs of therapy. In most cases, the high hygroscopicity of lithium salts makes them unsuited for commercialization. Therefore, we have recently evaluated the hygroscopicity of solid solutions of lithium coordination polymers. ${ }^{12}$

The mechanism of action of lithium remains largely unknown. ${ }^{8,13}$ Nonetheless, it is widely accepted that the metabolism of the drug is closely dependant on that of sodium. A low sodium concentration in the serum reduces the clearance of lithium, which causes intoxication. A drug product that contains an optimal ratio of lithium and sodium could reduce toxicity and a solid solution would have the advantage of allowing precise dosage of the cations in a single phase.

Partial solubility of lithium and sodium has been reported for niobate ${ }^{14,15}$ and metazirconate ${ }^{16}$ ceramics. On the contrary, examples of mixed crystals (molecular) of the two cations remains unknown. This work reports the first solid solution of lithium and sodium salts with organic counter ions.

Lithium and sodium are two alkali metals whose van der Waals radii are $1.82 \AA$ and $2.27 \AA$ respectively, i.e. sodium is about $25 \%$ larger than lithium. ${ }^{17}$ The smaller radius makes lithium a much harder acid ( 35 versus $21 \mathrm{eV}$ ), and determines a rather different chemical and structural behaviour. Lithium and sodium appear to form a pair of isomorphous crystals with the monoaqua isoorotate (IOR) complex and dihydrogen citrate anion $\left(\mathrm{H}_{2} \mathrm{CIT}\right)$ (Fig. 1). Hence these systems represent ideal candidates to verify whether molecular solid solutions of lithium and sodium are possible in the series of $\mathrm{Li}_{x-1} \mathrm{Na}_{x} \mathrm{IOR} \cdot \mathrm{H}_{2} \mathrm{O}\left(\mathbf{1}_{x}\right)$, and $\mathrm{Li}_{x-1} \mathrm{Na}_{x} \mathrm{H}_{2} \mathrm{CIT}\left(\mathbf{2}_{x}\right)$ (where $0>x>1$ ). 
<smiles>O=C(O)c1c[nH]c(=O)[nH]c1=O</smiles>

isoorotic acid<smiles>O=C(O)CC(O)(CC(=O)O)C(=O)O</smiles>

Fig. 1 Molecular structure for isoorotic acid and citric acid.

The monohydrate salts of lithium and sodium isoorotate crystallise in the $P 2_{1} / n$ space group and have roughly the same unit cell metrics $\left(\mathrm{CSD}^{18}\right.$ refcodes VEYVUQ ${ }^{19}$ and ACUFIO, ${ }^{20}$ respectively). Crystal isomorphism occurs in spite of the different chemical structure of the two compounds. A behaviour that has been referred to as pseudo-isomorphism. ${ }^{21,22}$ The lithium ion coordinates with five oxygen atoms forming a distorted trigonal bipyramid while the sodium salt with six oxygen atoms in an octahedral manner (Fig. 2). In both cases, IOR chelates the metal atoms with one carboxylate and one keto oxygen. Two of such complexes from a dimer with the carboxylate oxygen bridging between two metals $\left[\left\{\mathrm{M}_{2}(\mathrm{IOR}-\kappa \mathrm{O}, \mu \mathrm{O})_{2}\right\}\right]$. Above and below the plane of the dimer, two water molecules link the dimers into a 1D polymer (ladder). Such arrangement ensures the $\pi$ stacking of the aromatic rings. In NaIOR $\cdot \mathrm{H}_{2} \mathrm{O}$ the distorted octahedral coordination sphere is completed by a further interaction with the carboxylate oxygen from the IOR below in the same polymeric chain: O-Na distance $=2.47 \AA$. In LiIOR.

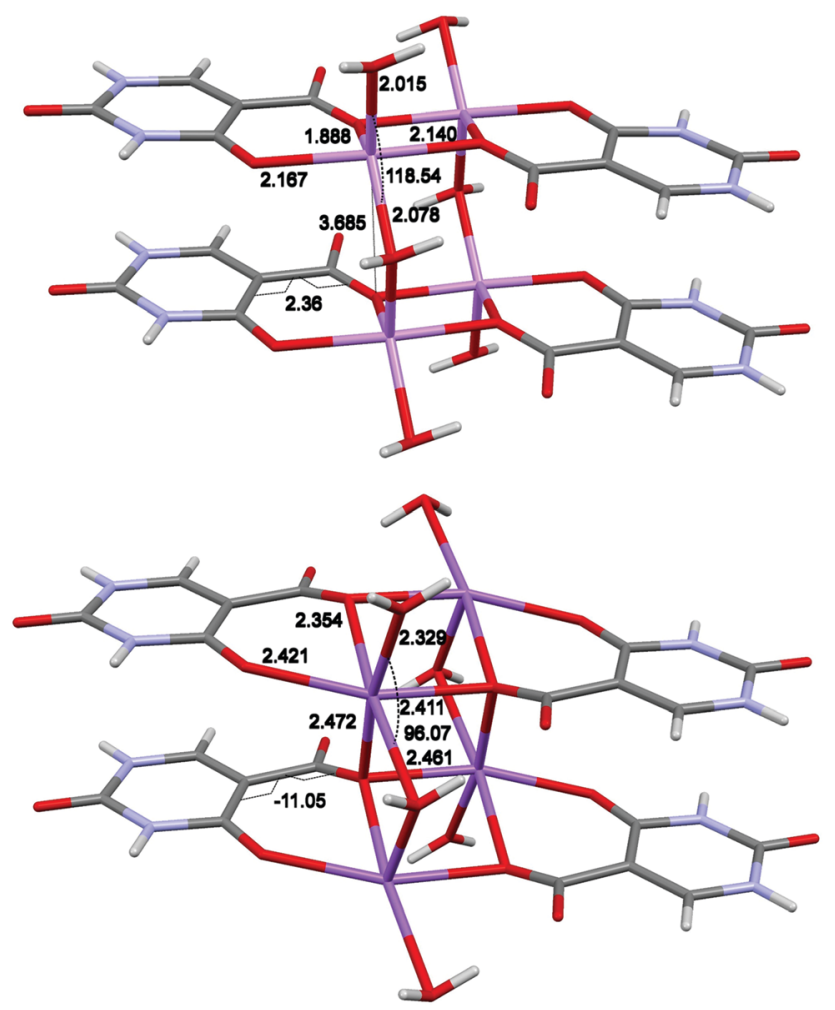

Fig. 2 Molecular structure in LilOR. $\mathrm{H}_{2} \mathrm{O}$ (top) and $\mathrm{NalOR} \cdot \mathrm{H}_{2} \mathrm{O}$ (bottom). Selected atomic distances and torsion angle are reported.

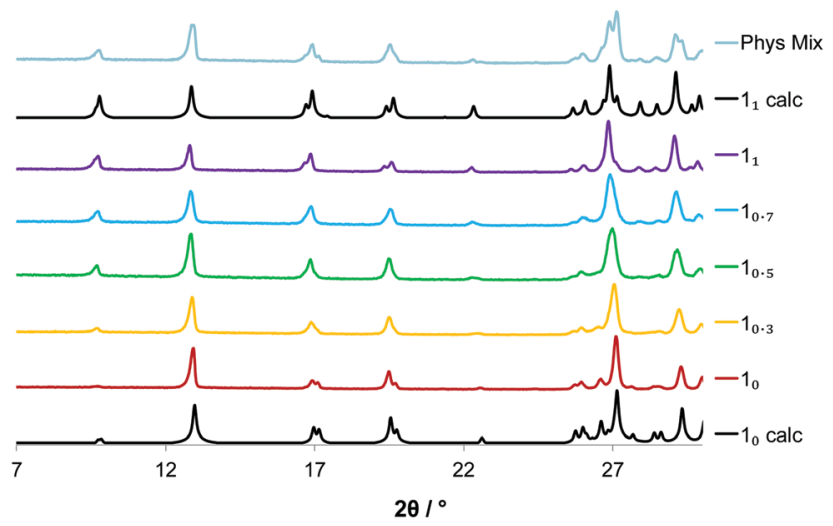

Fig. 3 PXRD pattern for $\mathrm{Li}_{x-1} \mathrm{Na}_{x} \mathrm{IOR} \cdot \mathrm{H}_{2} \mathrm{O}\left(\mathbf{1}_{\mathbf{x}}\right)$. The reference patterns are in black. Phys. mix is the 1:1 physical mixture of the parent.

$\mathrm{H}_{2} \mathrm{O}$ such interaction is absent: O-Li distance $3.68 \AA$. Therefore, the resulting underlying net topology is 2,3,5C2 and 2,2,4C1 for sodium and lithium respectively. The different coordination confers a different conformation to the two compounds. In LiIOR $\cdot \mathrm{H}_{2} \mathrm{O}$ the angle between water molecules is $118.5^{\circ}$, and the carboxylate group lays on the plane of the aromatic ring dihedral angle $2.4^{\circ}$. In NaIOR $\cdot \mathrm{H}_{2} \mathrm{O}$ the same angles measures $96.1^{\circ}$ and $-11.0^{\circ}$ respectively; i.e. the carboxylate group is rotated towards the upper dimer (Fig. 2 and Tables S1, S2, ESI $\dagger$ ). Ultimately, in the lithium complex, the metal ions lay almost in the plane common to the aromatic rings (about $0.08 \AA$ ). In the sodium complex, such distance increases to about $0.45 \AA$ A. For these reasons, the default calculation of crystal packing similarity ${ }^{23}$ as implemented in Mercury ${ }^{24}$ shows a partial matching (RMS $0.408,8$ out of 15 molecules), but only if molecular and bond counts differences are allowed.

The salt can be produced mechanochemically from basic metal salts $^{25}$ by grinding the carbonate salts with one equivalent of isoorotic acid. PXRD analysis reveals that similar phases form when the synthesis of intermediate $\mathrm{Li}$ and $\mathrm{Na}$ stoichiometry is attempted (Fig. 3). In the series of powder patterns, peaks shift regularly with composition. A comparison with the $1: 1$ physical mixture of LiIOR $\cdot \mathrm{H}_{2} \mathrm{O}$ and $\mathrm{NaIOR} \cdot \mathrm{H}_{2} \mathrm{O}$ suggests that the mixed salts are a homogeneous phases, i.e. a solid solution. Rietveld analysis of the mechanochemical product enabled the refinement of the unit cell metric for the series. As expected, unit cell parameters change linearly with composition, following the Vegard's law (ESI $\dagger$ ). Recrystallization of the samples with mixed composition affords single crystals for X-ray characterization, which confirmed the homogeneous (solid solution) nature of the mixed salts. The structures with mixed composition show the water molecule disordered over two positions and the thermal ellipsoids of the metals are oblate, as expected from atoms that are disordered over two positions. Then the coordination geometry of the mixed salts is an average of both parent compounds. Notably the metal centres in the mixed salt lay at about 0.34 and $0.42 \AA$ from the plane of the aromatic rings depending on the $\mathrm{Li} / \mathrm{Na}$ ratio.

Thermogravimetric analysis shows that the elimination of the coordinated water molecule occurs at lower temperature when the sodium content increases (Fig. 4). This is likely due to 


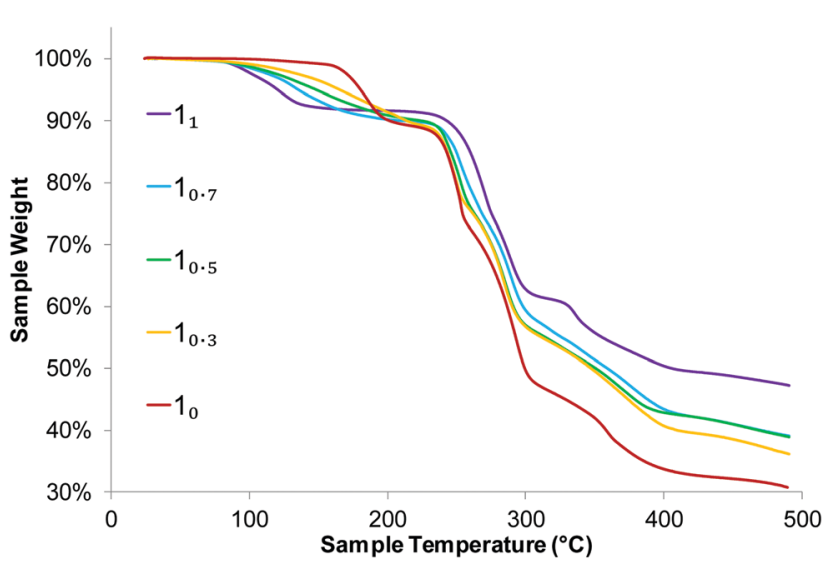

Fig. 4 Thermograms for $\mathrm{Li}_{x-1} \mathrm{Na}_{x} \mathrm{IOR} \cdot \mathrm{H}_{2} \mathrm{O}\left(\mathbf{1}_{\mathbf{x}}\right)$.

both the harder acidity of lithium and the different coordination geometry. In any case, the samples are stable at least until $100{ }^{\circ} \mathrm{C}$. DVS measurement shows that water uptake is higher for the samples with mixed composition than for the pure Li and Na salts, or the physical mixture (ESI $\dagger$ ). Nonetheless, it remains always below $1 \%$ resulting non-hygroscopic according to the European Pharmacopeia classification. ${ }^{26}$ Measurements of particle size distribution exclude that such behaviour is a consequence of different particle size, which are rather uniform throughout the series (Fig. 5). It is worth noting that in our previous investigation, solid solutions of lithium coordination polymers with L-proline and 2-methoxybenzoate/benzoate showed partial solubility and that the water uptake for the mixed compositions were higher than that of the end members. On the other hand, solid solutions formed by lithium coordination polymers with succinate/malate showed complete solubility and that the water uptake behaviour appeared to be more regular. ${ }^{12}$

Lithium and sodium form a pair of isomorphous crystals with the dihydrogen citrate anion. The structures are reported in the $P 2_{1} / a$ space group (CSD refcode LIHCIT $^{27}$ and NAHCIT ${ }^{27}$ respectively) with the metal atoms coordinated to six oxygens in an octahedral manner. A hydrate $\mathrm{LiH}_{2} \mathrm{CIT} \cdot \mathrm{H}_{2} \mathrm{O}$ (CSD refcode $\mathrm{ZZZREG}^{28}$ ), whose atomic coordinates are not determined, and a second form of $\mathrm{NaH}_{2} \mathrm{CIT}$ (CSD refcode NAHCIT01) ${ }^{29}$ which crystallizes in the orthorhombic $P 2_{1} 2_{1} 2_{1}$, are also known. In form II, the sodium atom coordinates to seven oxygen atoms.

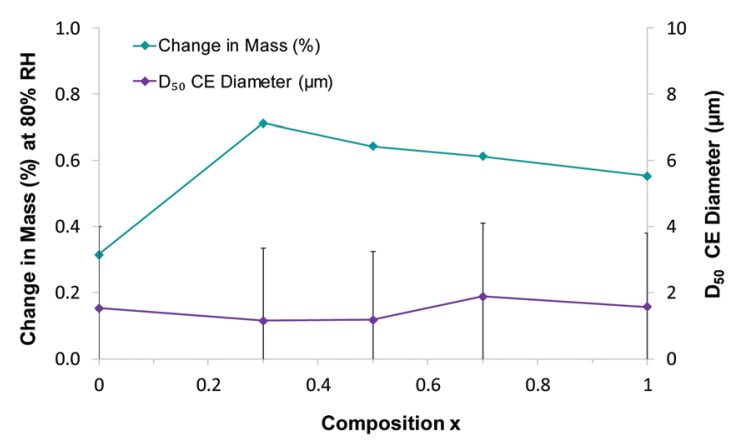

Fig. 5 Water sorption (blue) and particle size distribution (purple) as function of composition in $\mathrm{Li}_{x-1} \mathrm{Na}_{x} \mathrm{IOR} \cdot \mathrm{H}_{2} \mathrm{O}\left(\mathbf{1}_{\mathbf{x}}\right)$.

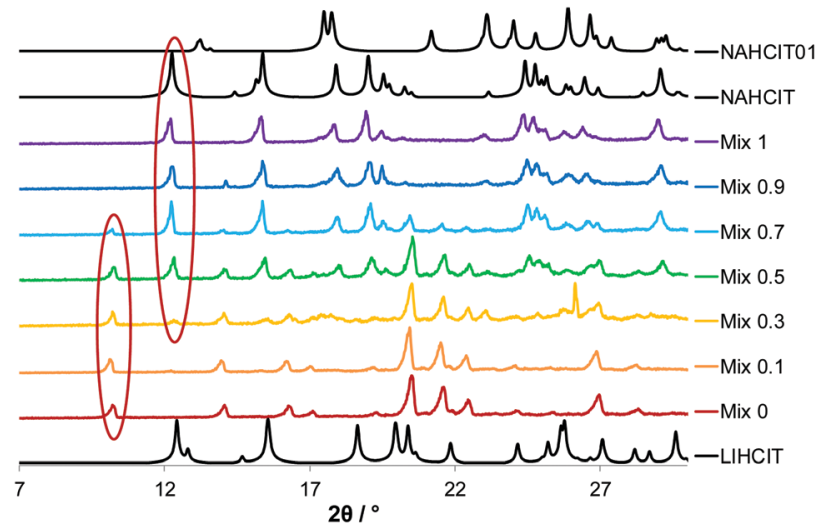

Fig. 6 Diffraction patterns for the product of manual grinding of citric acid with $\mathrm{LiH}_{2} \mathrm{CIT}$ and $\mathrm{NaH}_{2} \mathrm{ClT}$ in variable ratio. The reference patterns are in black.

PXRD analysis shows that co-grinding $\mathrm{Li}_{2} \mathrm{CO}_{3}$ or $\mathrm{Na}_{2} \mathrm{CO}_{3}$ with one equivalent of citric acid results in the hydrate $\mathrm{LiH}_{2} \mathrm{CIT}$ and $\mathrm{NaH}_{2} \mathrm{CIT}$ form I respectively (Fig. 6). Co-grinding of citric acid with both $\mathrm{Li}$ and $\mathrm{Na}$ in variable ratio affords physical mixtures of the above phases rather than the desired $\mathrm{Li}_{x-1} \mathrm{Na}_{x} \mathrm{H}_{2} \mathrm{CIT}\left(\mathbf{2}_{\boldsymbol{x}}\right)$ solid solution. Thermogravimetric analysis confirmed these conclusions: the first member of the series shows a weight loss about $7 \%$ between 100 and $150{ }^{\circ} \mathrm{C}$ as expected for pure $\mathrm{LiH}_{2} \mathrm{CIT}$ monohydrate, whereas in $\mathrm{NaH}_{2} \mathrm{CIT}$ the weight loss only starts at about $190{ }^{\circ} \mathrm{C}$ and coincides with the decomposition of the anion. The samples with mixed composition show an intermediate behaviour (see ESI $\dagger$ ). Notably the monoclinic form I of $\mathrm{NaH}_{2} \mathrm{CIT}$ converts in the thermodynamically stable form II in about two weeks (see ESI†).

In order to verify whether the formation of $\boldsymbol{2}_{\boldsymbol{x}}$ was possible in the absence of water, the samples were dried in a vacuum oven at $100{ }^{\circ} \mathrm{C}$ overnight and then re-ground with dry ethanol. PXRD analysis shows that such treatment produces anhydrous $\mathrm{LiH}_{2-}$ CIT. However, new peaks appear in all the samples that contain a portion of sodium, which coincide to the orthorhombic polymorph (Fig. 7).

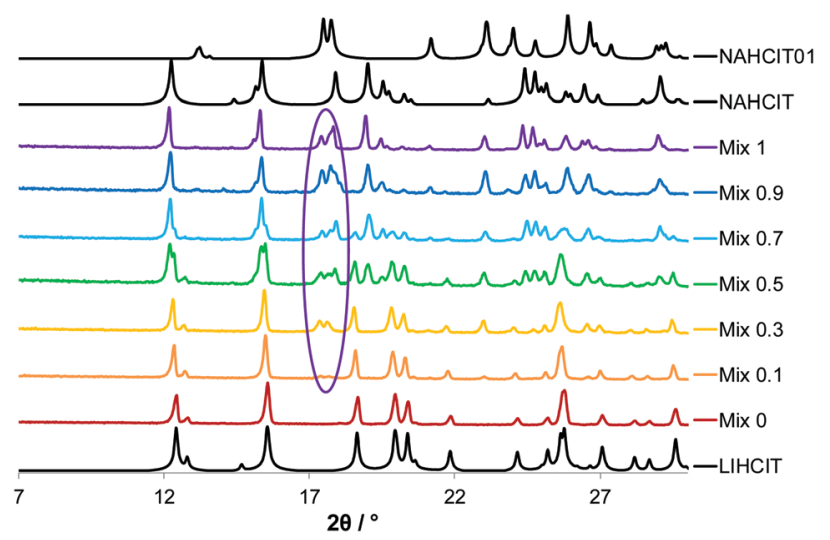

Fig. 7 Diffraction patterns for the product of manual grinding of citric acid with $\mathrm{LiH}_{2} \mathrm{ClT}$ and $\mathrm{NaH}_{2} \mathrm{ClT}$ in variable ratio in anhydrous conditions. The reference patterns are in black. 
Table 1 Phase quantification

\begin{tabular}{|c|c|c|c|c|c|}
\hline & \multicolumn{2}{|c|}{ Expected (wt\%) } & \multicolumn{3}{|c|}{ Found (wt\%) } \\
\hline & $\mathrm{Li}$ & $\mathrm{Na}$ & LIHCIT & NAHCIT & NAHCIT01 \\
\hline Mix 0.1 & 89.28 & 10.72 & $86.7(4)$ & $4.8(9)$ & $8.4(3)$ \\
\hline Mix 0.3 & 64.34 & 31.66 & $64.7(3)$ & - & $35.3(6)$ \\
\hline Mix 0.5 & 48.05 & 51.95 & $43.7(7)$ & $44.0(8)$ & $12.2(5)$ \\
\hline Mix 0.7 & 28.39 & 71.61 & $19(1)$ & $62.3(2)$ & $18.6(9)$ \\
\hline Mix 0.9 & 9.32 & 90.68 & - & $52.8(3)$ & $47.2(8)$ \\
\hline
\end{tabular}

A quantification of the mixture composition by Rietveld refinement indicates that the amount of $\mathrm{LiH}_{2} \mathrm{CIT}$ phase is generally lower than expected from the reactants stoichiometry (Table 1). The difference is always small (4 to 10\%) and close to limits of detections of this technique for organic samples with an in-house diffractometer. Therefore, the solubility of lithium and sodium dihydrogen citrate cannot be confirmed.

This work demonstrates that, despite the large different size and chemical properties, lithium and sodium can homogeneously mix in a single phase when they are combined with the appropriate anion. In the case of isoorotate salt, a virtually complete solubility exists despite the different coordination geometry in the parent compounds. On the other hand, in the isomorphous and isostructural dihydrogen citrate system, the extent of solid-state solubility is, at most, limited. These observations are in open contrast with Hume-Rothery rules.

We speculate that, in the non-isostructural isoorotate system, the high solubility is enabled by the presence of a water molecule that can freely pivot between the lithium and sodium coordination without affecting the overall crystal packing. In contrast, the low solubility it the citrate system could be explained by the existence of more stable solid forms (a hydrate and a polymorph). In a previous work we demonstrated that, solid solution could serve to control polymorphism in a series $\mathrm{Co} / \mathrm{Zn}$ coordination polymer. ${ }^{30}$ Here that effect is not observed.

Ultimately, we have presented the first example of molecular solid solution of lithium and sodium salts. This phase shows enough thermal and humidity stability to be employable as lithium drug substances medical therapy. From a pharmaceutical point of view, such mixed salt could help regulating the sodium concentration in the serum and the metabolism of lithium in the treatment of bipolar disorder.

The authors acknowledge the financial support of Science Foundation Ireland that contributed with Grant 15/SIRG/3577.

\section{Conflicts of interest}

The authors have no conflicts to declare.

\section{Notes and references}

1 A. H. Goldberg, M. Gibaldi and J. L. Kanig, J. Pharm. Sci., 1965, 54, 1145-1148.

2 M. Lusi, Cryst. Growth Des., 2018, 18, 3704-3712.

3 M. Lusi, CrystEngComm, 2018, 20, 7042-7052.

4 W. Hume-Rothery, J. Inst. Met., 1926, 35, 295-361.

5 W. D. Callister and D. G. Rethwisch, Materials Science and Engineering: An Introduction, Wiley, 8th edn, 2009.

6 A. I. Kitaigorodskii, Mixed crystals, Springer-Verlag, Berlin, 1984.

7 E. Schur, E. Nauha, M. Lusi and J. Bernstein, Chem. - Eur. J., 2015, 21, 1735-1742.

8 R. Oruch, M. A. Elderbi, H. A. Khattab, I. F. Pryme and A. Lund, Eur. J. Pharmacol., 2014, 740, 464-473.

9 D. Braga, F. Grepioni, L. Maini, D. Capucci, S. Nanna, J. Wouters, L. Aerts and L. Quéré, Chem. Commun., 2012, 48, 8219.

10 A. J. Smith, S.-H. Kim, N. K. Duggirala, J. Jin, L. Wojtas, J. Ehrhart, B. Giunta, J. Tan, M. J. Zaworotko and R. D. Shytle, Mol. Pharmaceutics, 2013, 10, 4728-4738.

11 N. K. Duggirala, M. L. Perry, Ö. Almarsson and M. J. Zaworotko, Chem. Commun., 2016, 52, 640-655.

12 M. Lestari, M. Lusi, A. O'Leary, D. O'Nolan and M. J. Zaworotko, CrystEngComm, 2018, 20, 5940-5944.

13 F. Marmol, Prog. Neuro-Psychopharmacol. Biol. Psychiatry, 2008, 32, 1761-1771.

14 T. Nitta, J. Am. Ceram. Soc., 1968, 51, 623-630.

15 R. C. R. Franco, E. R. Camargo, M. A. L. Nobre, E. R. Leite, E. Longo and J. A. Varela, Ceram. Int., 1999, 25, 455-460.

16 H. Pfeiffer, E. Lima and P. Bosch, Chem. Mater., 2006, 18, 2642-2647. 17 A. Bondi, J. Phys. Chem., 1964, 68, 441-451.

18 C. R. Groom, I. J. Bruno, M. P. Lightfoot and S. C. Ward, Acta Crystallogr., Sect. B: Struct. Sci., Cryst. Eng. Mater., 2016, 72, 171-179.

19 C. C. Wagner, E. J. Baran, O. E. Piro and E. E. Castellano, J. Inorg. Biochem., 1999, 77, 209-213.

20 G. S. Nichol and W. Clegg, Polyhedron, 2006, 25, 1043-1056.

21 G. Y. Chao and J. D. McCullough, Acta Crystallogr., 1961, 14, 940-945.

22 S. d'Agostino, D. Braga, F. Grepioni and P. Taddei, Cryst. Growth Des., 2014, 14, 821-829.

23 J. A. Chisholm and S. Motherwell, J. Appl. Crystallogr., 2005, 38, 228-231.

24 C. F. Macrae, P. R. Edgington, P. McCabe, E. Pidcock, G. P. Shields, R. Taylor, M. Towler and J. van de Streek, J. Appl. Crystallogr., 2006, 39, 453-457.

25 C. J. Adams, M. A. Kurawa, M. Lusi and A. G. Orpen, CrystEngComm, 2008, 10, 1790-1795.

26 European Pharmacopoeia, Directorate for the Quality of Medicine \& Healthcare of the Council of Europe (EDQM), Strasburg, 8th edn, 2013, p. 695.

27 J. P. Glusker, D. Van Der Helm, W. E. Love, M. Dornberg, J. A. Minkin, C. K. Johnson and A. L. Patterson, Acta Crystallogr., 1965, 19, 561-572.

28 W. E. Love and A. L. Patterson, Acta Crystallogr., 1960, 13, 426-428.

29 A. Rammohan and J. A. Kaduk, Acta Crystallogr., Sect. E: Crystallogr. Commun., 2016, 72, 854-857.

30 C. J. Adams, A. L. Gillon, M. Lusi and A. G. Orpen, CrystEngComm, $2010,12,4403$. 